\title{
GUIMARÃES ROSA, LEITOR DE SIMÕES LOPES NETO: PRÁTICAS DE LEITURA E AFINIDADES HISTÓRICO- LITERÁRIAS
}

\begin{abstract}
Jocelito Zalla ${ }^{1}$
Resumo: Este texto toma o problema da confluência formal entre as obras de João Simões Lopes Neto (1865-1916) e João Guimarães Rosa (1908-1967), através de uma fonte inédita: o exemplar anotado por Rosa da edição crítica de Contos Gauchescos e Lendas do Sul (1949), de Simões. Analiso a leitura particular do escritor mineiro e interpreto as suas condições históricas de realização, além de apontar para a nova recepção do autor gaúcho no campo literário nacional dos anos 1950. Como métodos, recorro a uma tipologia das marcas de leituras e suas funções, seguida de uma história comparada das formas e projetos literários. Os resultados apontam para as práticas de leitura como investigação de linguagem, nos anos que precederam à publicação de Grande Sertão: Veredas (1956), e afinidades estéticas regionalistas profundas, motivadas por problemas histórico-culturais semelhantes em tempos-espaços diversos, e ampliadas pela ressignificação modernista do regionalismo simoniano.
\end{abstract}

Palavras-chave: Guimarães Rosa. Simões Lopes Neto. Práticas de leitura. Regionalismo e Modernismo.

\section{GUIMARÃES ROSA, SIMÕES LOPES NETO'S READER: READING PRACTICES AND HISTORICAL-LITERARY AFFINITIES}

\begin{abstract}
This text takes the problem of the formal confluence between the works of João Simões Lopes Neto (1865-1916) and João Guimarães Rosa (1908-1967), through an unprecedented source: the copy annotated by Rosa of the critical edition of Contos Gauchescos e Lendas do Sul (1949), by Simões. I analyze the private reading of the writer from Minas Gerais and I interpret its historical conditions of realization, in addition to indicate the new reception of the author from Rio Grande do Sul in the national literary field of the 1950s. As methods, I resort to a typology of reading marks and their functions, followed of a comparative history of literary forms and projects. The results show Rosas' reading practices as a language investigation, in the years that preceded the publication of Grande Sertão: Veredas (1956), and deep regionalist aesthetic affinities, motivated by similar historical-cultural problems in different time-spaces, and amplified by modernist resignification of Simonian regionalism.
\end{abstract}

Keywords: Guimarães Rosa. Simões Lopes Neto. Reading practices. Regionalism and Modernism.

\section{GUIMARÃES ROSA, LECTOR DE SIMÕES LOPES NETO: PRÁCTICAS DE LECTURA Y AFINICIONES HISTÓRICO-LITERARIAS}

Resumen: Este texto aborda el problema de la confluencia formal entre las obras de João Simões Lopes Neto (1865-1916) y João Guimarães Rosa (1908-1967), a través de una fuente inédita: la copia anotada por Rosa de la edición crítica de Contos Gauchescos e Lendas do Sul (1949), de Simões. Analizo la lectura privada del escritor Minas Gerais e interpreto sus condiciones históricas de realización, además de señalar la nueva acogida del autor gaucho en el campo literario nacional de los años 50. Como métodos, recurro a una tipología de la marcas de lecturas y sus funciones, seguidas de una historia comparada de formas y proyectos literarios. Los

\footnotetext{
${ }^{1}$ Doutor em História Social pela Universidade Federal do Rio de Janeiro (UFRJ), com estágio-sanduíche na Université Paris-Sorbonne (Paris-IV). Licenciado, bacharel e mestre em História pela Universidade Federal do Rio Grande do Sul (UFRGS). Professor do Colégio de Aplicação e do Programa de PósGraduação em História da UFRGS. Professor do programa nacional de Mestrado Profissional em Ensino de História (PROFHistória).
} 
resultados apuntan a las prácticas lectoras como investigación del lenguaje, en los años que precedieron a la publicación de Grande Sertão: Veredas (1956), y afinidades estéticas regionalistas profundas, motivadas por problemas histórico-culturales similares en diferentes espacios-temporales, y amplificadas por la modernidad. resignificación del regionalismo simoniano.

Palabras clave: Guimarães Rosa. Simões Lopes Neto. Prácticas de lectura. Regionalismo y Modernismo.

\section{Introdução}

Muitos críticos e estudiosos da literatura já notaram certa confluência entre os contos de João Simões Lopes Neto (1865-1916) e a obra de João Guimarães Rosa (19081967), como no exemplo: “João Guimarães Rosa, ampliando e aprofundando o legado de Simões Lopes Neto, transpõe o fosso aberto entre a voz do narrador culto e a voz do personagem iletrado ou semiletrado e, através do uso frequente do indireto livre, elide a distância entre um e outro, misturando pontos de vista e colocando em contato duas esferas diversas de experiência" (VASCONCELOS, 1997/1998, p. 83). Geralmente, portanto, chamam a atenção para o trabalho de linguagem, na incorporação da oralidade à escrita, e para o foco narrativo semelhante. O campeiro gaúcho Blau Nunes poderia ser um precursor do sertanejo Riobaldo, de Grande Sertão: Veredas (1956). Idêntica solução narrativa protagonistas-narradores populares, que apresentam seu ponto de vista sobre as narrativas, permitindo um mergulho na cultura representada. Segundo Luís Augusto Fischer: "as soluções que o escritor gaúcho encontrou abriram caminho para a grande obra, para a obra maior e mais bem acabada de Guimarães Rosa” (FISCHER, 2014, p. 179). Por conta disso, não é raro encontrarmos alguma especulação sobre possível influência de Simões Lopes Neto em Guimarães Rosa. Teria o autor mineiro descoberto tais estratégias na leitura dos Contos Gauchescos?

Infelizmente, não acredito que cheguemos a uma resposta conclusiva. Primeiro, é impossível comprovar um nexo causal deliberado entre os dois textos. Diferentemente de outros escritores, como os também sulistas Erico Verissimo e Barbosa Lessa ${ }^{2}$, Guimarães Rosa não deixou, salvo engano, nenhum comentário crítico ou manifestação escrita sobre

\footnotetext{
2 Talvez os principais "herdeiros” simonianos em ficção no Rio Grande do Sul. Erico Verissimo incorporou várias das lendas de Simões Lopes Neto à composição de sua trilogia O tempo e o vento (1949-1961), inclusive como inspiração de personagens novas, além de uma perspectiva semelhante de contra-memória histórica, dando voz aos grupos marginalizados na historiografia tradicional sul-rio-grandense da época (camadas populares, mulheres, indígenas, negros). Barbosa Lessa, além da exploração de temas, de personagens e de idêntica perspectiva popular, também publicou uma obra de contos com a estética gauchesca proposta por Simões Lopes Neto no Brasil, à exemplo do gênero gauchesco desenvolvido na Argentina e no Uruguai ( $O$ boi das aspas de ouro, 1956). Ambos declararam, por diversas vezes, sua admiração e/ou dívida para com o escritor pelotense da Primeira República.
} 
a impressão que a leitura de Simões lhe propiciou, muito menos o considerou, em discurso público, como um precedente. Segundo, não há usos de motivos/temas simonianos na fatura literária, o que contribuiria para avaliar seu impacto na nova narrativa. As similaridades de linguagem poderiam, inclusive, ser creditadas à matéria comum: a experiência de homens e mulheres do campo, um mundo compartilhado de tradição oral em regiões de economia periférica no país. Restaria, então, a narração homodiegética. $O$ grande "achado" de Simões, para a crítica, é também o ponto alto do romance de Rosa. Para Willi Bolle, por exemplo, é essa estratégia que permite ao mineiro superar $O s$ sertões, de Euclides da Cunha, intervindo definitivamente na maneira com a qual a intelectualidade brasileira encara o universo rural: "as questões estruturais mal resolvidas no livro de Euclides - o modo de narrar, a figura do narrador e o problema social - são radicalmente reelaboradas em Grande Sertão: Veredas" (BOLLE, 2004, p. 39). Mas outra observação do mesmo crítico permite estabelecer uma diferença: "o seu narrador sertanejo, note-se bem, não é nada 'simples', mas uma pessoa que conhece muito bem a gramática e a retórica, uma figura altamente elaborada, um jagunço letrado" (BOLLE, 2004, p. 41). É verdade que o narrador de Simões Lopes Neto poderia ser descrito como um homem de "inteligência aguda". Como lembrado por Fischer, Blau Nunes era "vivido, experimentado, calejado das batalhas, capaz de entender muito do estranho mundo humano" (FISCHER, 2014, p. 184). Mas não era um letrado. Pode-se argumentar que esse traço não descarta totalmente uma apropriação, ainda que, a partir dele, outros autores brasileiros tenham de ser considerados como precedentes e fontes ${ }^{3}$.

De qualquer forma, é certo que Guimarães Rosa leu Simões Lopes Neto. E é muito provável que essa leitura tenha ocorrido entre a publicação de Sagarana (1946) e a redação de Grande Sertão: Veredas. Em 1950, Aurélio Buarque de Holanda presenteou Rosa com um volume da edição crítica de Contos e Lendas, que acabara de organizar para a Editora Globo, de Porto Alegre. O exemplar está disponível para consulta no acervo do escritor, hoje depositado no Instituto de Estudos Brasileiros (IEB-USP). Há nele algumas anotações e muitos trechos sublinhados. O prefácio crítico do poeta e ensaísta Augusto Meyer, então diretor do Instituto Nacional do Livro, e a introdução escrita por Holanda foram marcados do começo ao fim. Alguns contos e lendas também. Mas não é possível afirmar que todos os textos simonianos tenham sido lidos. Por fim, há destaques a lápis

\footnotetext{
${ }^{3}$ Por exemplo, Graciliano Ramos, com seu Paulo Honório, o protagonista-narrador de São Bernardo (1934). Também narrado em primeira pessoa, o romance apresenta um protagonista letrado, mas oriundo das classes populares, órfão criado por uma doceira e que passou a adolescência trabalhando na roça.
} 
no glossário especializado em regionalismos dialetais da fronteira Sul, também estabelecido por Holanda, que acompanha do texto de Simões. Esse conjunto de marcas compõe um testemunho de leitura. Um documento valioso, portanto, para se pensar sobre a recepção da obra de Simões Lopes Neto nos anos 1950, incluindo as mediações de sentido oferecidas pelos paratextos editoriais ${ }^{4}$, e sobre o projeto estético em construção de Guimarães Rosa. Neste artigo, buscarei analisar a leitura documentada que Guimarães Rosa fez do escritor gaúcho, na temporalidade dessa edição póstuma consagradora, e interpretar suas condições históricas de realização.

\section{Marcas de leitura e investigação de linguagem}

Acredito que a primeira coisa a se fazer para a compreensão da fonte é uma análise descritiva das marcas de leitura. A partir daí, talvez consigamos sondar alguma convenção obscura. Havia método na maneira com a qual Guimarães Rosa sinalizou os textos? O que ele revelaria sobre seus interesses? Grosso modo, o escritor utilizou três formas de destaque: sublinhados, pontos de interrogação e, em poucas vezes, repetição de palavras do original, na lateral do trecho em que elas aparecem (exemplo na Figura 1). No primeiro tipo, há marcas a lápis grafite e colorido, em vermelho e azul.

Figura 1: Reprodução de página da edição crítica de SLN (1949) anotada por

Guimarães Rosa

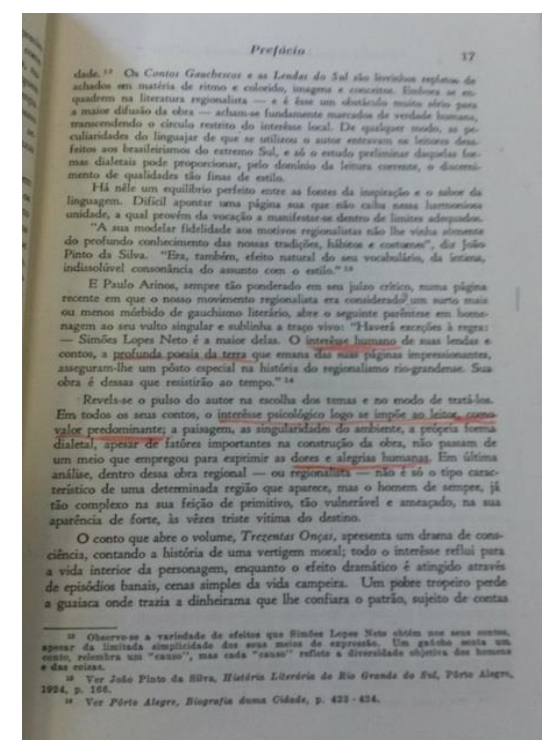

Fonte: IEB-USP

\footnotetext{
${ }^{4}$ Emprego as categorias de Gérard Genette (2009) para analisar os elementos paratextuais, tais como apresentações, textos críticos, prefácios e posfácios: discursos geralmente verbais que cercam e prolongam o texto principal na própria materialidade do livro; com funções de apresentação, ou seja, visando garantir a presença e controlar a recepção e o consumo da obra.
} 
Em sua tese sobre o processo de escrita do autor, Camila Rodrigues identificou como prática recorrente a anotação de seus manuscritos com um lápis de ponta dupla com tais cores. Sabendo que Rosa estabelecia uma correlação entre cores e sons, a historiadora acredita que a estratégia buscava ressaltar a "presença de heranças auditivas de experiências vocais": "ele estaria chamando a atenção para a construção de artifícios composicionais da vocalidade que já foram usados em sua escritura e que transparecem na escrita, como, por exemplo, o ritmo" (RODRIGUES, 2014, p. 124). Existiria, portanto, uma intencionalidade nas marcas da leitura das versões iniciais de seus próprios textos, como num código feito para se relacionar com essa matéria bruta em novos momentos de criação. Acredito que essa estratégia podia ser estendida a obras literárias por ele estudadas. Para isso, deveria configurar um protocolo suficientemente aberto para se adequar a cada nova situação de leitura. O estudo de Rodrigues pode apontar para essa direção. E o caso específico da leitura documentada da edição crítica de Simões Lopes Neto nos ajuda a reforçar ou refutar a hipótese.

Como expediente para decifrar a notação encontrada na fonte, isolei todas as sentenças e palavras realçadas por Guimarães Rosa, reagrupando os excertos de acordo com o tipo de marca. A partir disso, analisei a sintaxe, o léxico e suas funções na obra, reinserindo os trechos em seu contexto textual. Dessa maneira, foi possível identificar algumas afinidades entre eles, o que permitiu criar subdivisões na tipologia inicial, estabelecida pela materialidade dos destaques:

a) Sublinhados em vermelho (destacados abaixo por sublinhado preto): indicam ambiência rural e traços linguístico-culturais do regionalismo gaúcho (ex. 1). Na crítica de Augusto Meyer, também são utilizados para destacar características do projeto estético de Simões Lopes (ex. 2):

Ex. 1:

De chapéu de aba larga, botado no cocuruto da cabeça e preso num barbicacho de borlas morrudas, passado pelo nariz; no pescoço um lenço colorado, com o nó republicano; na cintura um tirador de couro de lontra debruado de tafetá azul e mais cheio de cortados do que manchas tem um boi salino! (NETO, 1949, p. 133).

Ex. 2:

O interesse humano de suas lendas e contos, a profunda poesia da terra que emana das suas páginas impressionantes, asseguram-lhe um posto especial na história do regionalismo rio-grandense (NETO, 1949, p. 17). 
b) Sublinhados em azul (destacados na transcrição abaixo em negrito): indicam construções estilísticas do autor através de deslocamentos na sintaxe (ex. 1) e linguagem metafórica (ex. 2):

Ex. 1:

Na pabulagem, andava sozinho: quando falava, era alto e grosso e sem olhar para ninguém (NETO, 1949, p. 133).

Ao invés de:

"Na pabulagem, andava sozinho: falava alto e grosso, sem olhar para ninguém".

Ex. 2:

...- e uma, duas, dez, vinte, cinquenta vezes cravou o ferro afiado, como quem espicaça uma cruzeira numa toca... como quem quer estraçalhar uma cousa nojenta... como quem quer reduzir a miangos uma prenda que foi querida e na hora é odiada!... (NETO, 1949, p. 19)

c) Marcações simples a lápis grafite (aqui transcritas com os destaques originais em itálico da edição): investigação no plano semântico, ressaltando arcaísmos e léxico popular (palavras isoladas e expressões/fórmulas).

Ex. 3:

"muitos casos: inté, entonce (ou entonces), despois, saluço, premeiro, dereito, proguntar, malenconia, malino, sino-samão ("signo-salomão"); sugigar, Anrique, escuitar, contino, corgo, esprital ('hospital'), ingrês (donde ingressa), fermoso"... (NETO, 1949, p. 30)

d) Ponto de interrogação a lápis grafite: estabelece relações com a crítica de Meyer e Holanda, aparentemente indicando estranhamento ou discordância em relação a alguma assertiva.

Ex. 4:

E Paulo Arinos, sempre tão ponderado em seu juízo crítico, numa página recente em que o nosso movimento regionalista era considerado [?] um surto mais ou menos mórbido de gauchismo literário (NETO, 1949, p. 17).

e) Risco vertical a lápis grafite: seleciona períodos em que o próprio autor ou seu livro de contos, Sagarana, são citados nos paratextos.

Ex. 5:

...um Monteiro Lobato, um José Lins do Rego, uma Raquel de Queiroz, um Luís Jardim, um José Américo de Almeida, um Guimarães Rosa, que mantém a verdade essencial da fala de seus tipos sem descer ao servilismo da fotografia (NETO, 1949, p. 28) 
No segundo momento da análise, inferi possíveis funções da marcação na situação de leitura, incluindo os eventuais interesses de Guimarães Rosa. A partir do confronto dessa tipologia com os sinais específicos dos três textos maiores da edição crítica (Meyer, Holanda e Simões Lopes) ${ }^{5}$, elaborei um quadro descritivo que me permitiu organizar todo o material, conforme desdobrado a seguir.

Quadro 1: Marcações de leitura de Guimarães Rosa no prefácio de Augusto Meyer

\begin{tabular}{|c|c|c|c|c|c|}
\hline Cor/tipo & \multicolumn{2}{|c|}{ Interesse } & Ocorrências & Funções do trecho no texto & $\begin{array}{c}\text { Funções (possíveis) do trecho } \\
\text { na leitura }\end{array}$ \\
\hline \multirow[t]{2}{*}{ Vermelho } & \multirow[t]{2}{*}{$\begin{array}{l}\text { Regio- } \\
\text { nalismo } \\
\text { literário }\end{array}$} & Cor local & $\begin{array}{l}\text { “"horizontes/horizonte" (p. 11) } \\
\text { “manacá do Norte" (p. 15) } \\
\text { "primaverinha" (p. 15) }\end{array}$ & - Designa ambiência. & - Destaca ambiência. \\
\hline & & $\begin{array}{l}\text { Projeto } \\
\text { simoniano }\end{array}$ & $\begin{array}{l}\text { “interesse humano" (p. 17) } \\
\text { "profunda poesia da terra" (p. 17) } \\
\text { “interesse psicológico logo se impõe ao leitor, } \\
\text { como valor predominante” (p. 17) } \\
\text { "Wores e alegrias humanas" (p. 17) } \\
\text { “em sobrecarregar a descrição do pitoresco" } \\
\text { (p. 18) } \\
\text { "São contos de sangue e paixão" (p. 18) } \\
\text { “absurdo moral da criatura" (p. 19) } \\
\text { “o movimento da ação" (p. 19) }\end{array}$ & $\begin{array}{l}\text { - Indica características } \\
\text { literárias. }\end{array}$ & $\begin{array}{l}\text { - Destaca características } \\
\text { literárias/ chaves para a leitura } \\
\text { da obra. }\end{array}$ \\
\hline
\end{tabular}

${ }^{5}$ O prefácio de Augusto Meyer antecede a apresentação de Aurélio Buarque de Holanda. Possui uma dupla função de apresentação e de atestado crítico de especialista em letras gaúchas, como vinha se constituindo o poeta modernista nos anos 1940 (o mesmo texto já havia sido publicado em seu livro de ensaios sobre o tema, Prosa dos Pagos, lançado em 1941 e revisado e ampliado at). Também há um quarto texto na composição da edição crítica, de caráter biográfico e informativo, publicado como posfácio. Foi escrito pelo jornalista Carlos Reverbel, então jovem repórter da Revista do Globo, da mesma casa editora. 


\begin{tabular}{|c|c|c|c|c|c|}
\hline \multirow[t]{2}{*}{ Azul } & \multirow{2}{*}{$\begin{array}{l}\text { Constru- } \\
\text { ções } \\
\text { estilísti- } \\
\text { cas }\end{array}$} & $\begin{array}{l}\text { Deslocamen- } \\
\text { tos (sintaxe) }\end{array}$ & "ambivalência amorosa" (p. 19) & $\begin{array}{l}\text { - Recurso de estilo/ desvio da } \\
\text { norma culta }\end{array}$ & $\begin{array}{l}\text { - Ressalta estrutura atípica/ } \\
\text { recurso estilístico no nível da } \\
\text { sintaxe. }\end{array}$ \\
\hline & & $\begin{array}{l}\text { Metáforas/ } \\
\text { eufemismos } \\
\text { (semântica) }\end{array}$ & --- & --- & --- \\
\hline \multirow[t]{3}{*}{ Lápis } & \multirow{2}{*}{$\begin{array}{l}\text { Investi- } \\
\text { gação de } \\
\text { língua- } \\
\text { gem }\end{array}$} & Vocabulário & “verde-sol” (p. 11) & $\begin{array}{l}\text { - Recurso de estilo/desvio da } \\
\text { norma culta }\end{array}$ & $\begin{array}{l}\text { - Destaca recurso estilístico no } \\
\text { nível do léxico. }\end{array}$ \\
\hline & & $\begin{array}{l}\text { Provérbios/ } \\
\text { expressões } \\
\text { metafóricas }\end{array}$ & --- & --- & \\
\hline & Exceção & $\begin{array}{l}\text { Linguajar } \\
\text { local }\end{array}$ & "vez que outra" (p. 15) & $\begin{array}{l}\text { - Recurso de estilo/desvio da } \\
\text { norma culta }\end{array}$ & - Ressalta estrutura atípica. \\
\hline \multirow[t]{2}{*}{$\begin{array}{l}\text { Ponto de } \\
\text { interro- } \\
\text { gação }\end{array}$} & \multirow{2}{*}{\multicolumn{2}{|c|}{ Crítica paratextual }} & $\begin{array}{l}\text { "A sua obra tão breve e humilde merece um } \\
\text { estudo minucioso, sob o ponto de vista do } \\
\text { estilo e do vocabulário, pois é grande a riqueza } \\
\text { de pesquisa que propõe ao crítico" (p. 16) }\end{array}$ & $\begin{array}{l}\text { - Recomenda análise de } \\
\text { linguagem. }\end{array}$ & $\begin{array}{l}\text { Estranhamento com a } \\
\text { recomendação (?) em edição } \\
\text { crítica. }\end{array}$ \\
\hline & & & $\begin{array}{l}\text { "E Paulo Arinos, sempre tão ponderado em seu } \\
\text { juízo crítico, numa página recente em que o } \\
\text { nosso movimento regionalista era considerado } \\
\text { [?] um surto mais ou menos mórbido de } \\
\text { gauchismo literário" (p. 17) }\end{array}$ & $\begin{array}{l}\text { - Referência à fortuna crítica - } \\
\text { recurso de autoridade. }\end{array}$ & Discordância de avaliação (?) \\
\hline
\end{tabular}

Fonte: elaborado pelo autor.

Toda a leitura do livro pode ser descrita como uma investigação de linguagem, que passa pela observação de uma tradição inteira. Nos anos 1950, o regionalismo literário gaúcho passava por uma significativa renovação, a reboque da atualização dos temas locais no campo intelectual mais amplo do Rio Grande do Sul, finda a vigilância simbólica do Estado Novo sobre as elites regionais (CORADINI, 2003). Esse processo demandava o exame crítico da história literária do Extremo Sul. Tarefa empreendida, principalmente, pela geração modernista gaúcha, surgida no 
final dos anos 1920, que se encontrava então já consolidada na cena letrada e buscava selecionar seus precursores nobres, estabelecendo uma linhagem literária local que justificasse seu próprio projeto estético. Esse é o quadro cultural da reedição da obra de Simões Lopes Neto pela Globo, segunda maior casa editorial do Brasil àquela altura, única do Sul capaz de catapultar autores gaúchos ao cenário nacional. Nesse sentido, a escolha do filólogo em ascensão Aurélio Buarque de Holanda, então professor do Colégio Pedro II, para a organização e fixação crítica do texto era estratégica, apesar da ideia pertencer a Augusto Meyer (como demonstra sua leitura simoniana no ensaio Prosa dos Pagos, de 1941). Isso não significa que a revisão do cânone regional fosse artificial, ou seja, que não dependesse de leituras e trocas literárias entre seus autores. É o que nos faz crer a adesão de Erico Verissimo, até então reconhecido por seus romances urbanos, à temática histórica rural, na sua famosa trilogia $O$ tempo e o vento (1949-1961). Um projeto literário novo que passava pela releitura de personagens e teses simonianas; algo que já havia sido feito nas décadas anteriores por alguns poetas que pertenciam ao círculo da editora, dentre os quais o próprio Meyer (ZALLA, 2018).

Apenas Simões Lopes Neto, portanto, poderia abrigar na recepção de sua obra um projeto estético coletivo, representativo da parcela mais avançada da elite letrada regionalista/modernista do Rio Grande do Sul. Os paratextos da edição crítica corroboram essa avaliação, pois indicavam o texto simoniano como maior realização do regionalismo local, se não brasileiro, até então. O ponto de interrogação de Guimarães Rosa sobre o trecho de Meyer da página 16 (ver Quadro 1) pode indicar tanto um estranhamento pela recomendação de estudo da linguagem simoniana numa edição que trazia consigo uma introdução desse gênero (efeito da publicação sem alteração do já citado ensaio, anterior ao ingresso de Holanda no projeto) quanto uma surpresa pela caracterização da obra como "breve e humilde". Com certeza, não era essa a impressão que os editores pretendiam passar.

Sobre a leitura do texto crítico de Meyer, percebe-se em Rosa justamente um interesse pela dialética geral x particular. No primeiro polo, temos o destaque de aspectos psicológicos: "interesse humano", "dores e alegrias humanas", "absurdo moral da criatura", "contos de sangue e paixão". No segundo, também chama sua atenção a cor local: "profunda poesia da terra", "descrição do pitoresco". Um dos principais argumentos da nova crítica consagradora da obra de Simões Lopes Neto era atestar seu uso de matéria local como um meio de acesso a dilemas universais. A 
introdução de Holanda, aliás, constrói idêntico juízo. O que foi percebido e destacado por Rosa, na página 72 (ver Quadro 2), com ponto de interrogação. Diferentemente de regionalistas contemporâneos do gaúcho, haveria uma perfeita combinação entre paisagem e enredo nos Contos e Lendas. Acredito que essa dialética tenha servido mesmo como principal chave para a nova recepção do texto simoniano. Os aspectos linguísticoestilísticos foram subordinados a ela.

Quadro 2: Marcações de leitura de Guimarães Rosa na introdução de Aurélio Buarque de Holanda

\begin{tabular}{|c|c|c|c|c|c|}
\hline Cor/tipo & \multicolumn{2}{|c|}{ Interesse } & Ocorrências & $\begin{array}{c}\begin{array}{c}\text { Funções do trecho no } \\
\text { texto }\end{array} \\
\text { a }\end{array}$ & $\begin{array}{l}\text { Funções (possíveis) do } \\
\text { trecho na leitura } \\
---\end{array}$ \\
\hline \multirow[t]{3}{*}{ Vermelho } & \multirow{2}{*}{$\begin{array}{l}\text { Regionalis } \\
\text { mo } \\
\text { literário }\end{array}$} & \multirow{2}{*}{\begin{tabular}{|l|} 
Cor local \\
Projeto \\
simoniano
\end{tabular}} & \multirow{2}{*}{$\begin{array}{ll}--- \\
---\end{array}$} & \multirow[t]{2}{*}{---} & \\
\hline & & & & & \\
\hline & Exceção & Erro/estilo & $\begin{array}{l}\text { "portarem-se" (p. 27) } \\
\text { "O comum entre escritores regionalistas } \\
\text { é portarem-se ante o homem do povo } \\
\text { como espectador fino e sutil...". }\end{array}$ & $\begin{array}{l}\text { Uso informal: "portar- } \\
\text { se" por "comportar-se". }\end{array}$ & $\begin{array}{l}\text { - Destaca construção } \\
\text { atípica no nível do } \\
\text { léxico. }\end{array}$ \\
\hline \multirow[t]{2}{*}{ Azul } & \multirow{2}{*}{$\begin{array}{l}\text { Construçõ } \\
\text { es } \\
\text { estilísticas }\end{array}$} & $\begin{array}{l}\text { Deslocament } \\
\text { os (sintaxe) }\end{array}$ & --- & \multirow[t]{2}{*}{---} & \\
\hline & & $\begin{array}{l}\text { Metáforas/eu } \\
\text { femismos } \\
\text { (semântica) }\end{array}$ & --- & & \\
\hline $\begin{array}{l}\text { Ponto de } \\
\text { interrogação }\end{array}$ & \multicolumn{2}{|c|}{ Crítica paratextual } & $\begin{array}{l}\text { "A paisagem, na literatura do tempo de } \\
\text { Simões Lopes, era uma peça sobreposta } \\
\text { ao conto ou ao romance. Não fazia com }\end{array}$ & $\begin{array}{l}\text { - Ressalta } \\
\text { universalidade da } \\
\text { literatura simoniana - }\end{array}$ & $\begin{array}{l}\text { - Destaca avaliação } \\
\text { (relação forma e }\end{array}$ \\
\hline
\end{tabular}


DOI: 10.47694/issn.2674-7758.v3.i8.2021.122145

\begin{tabular}{|c|c|c|c|c|c|}
\hline & & & $\begin{array}{l}\text { eles um todo. Retirada da história, esta } \\
\text { funcionava perfeitamente" (p. 72) }\end{array}$ & $\begin{array}{l}\text { paisagem tinha função } \\
\text { estética. }\end{array}$ & $\begin{array}{l}\text { conteúdo - relação } \\
\text { regional e universal) }\end{array}$ \\
\hline \multirow[t]{2}{*}{$\begin{array}{l}\text { Lápis } \\
\text { (marcação } \\
\text { lateral) }\end{array}$} & $\begin{array}{l}\text { Investigação } \\
\text { de linguagem }\end{array}$ & \multicolumn{2}{|r|}{$\begin{array}{l}\text { "Ora são termos ou acepções de } \\
\text { uso quase unicamente literário. } \\
\text { É o caso de à sorrelfa, ou sobre } \\
\text { no sentido de 'após"”. (p. 34) } \\
\text { "fecunda" (p. } 71 \text { ) }\end{array}$} & $\begin{array}{l}\text { - Indica vocabulário de } \\
\text { português antigo, } \\
\text { sobreviventes na } \\
\text { linguagem do povo ou } \\
\text { em usos literários. }\end{array}$ & $\begin{array}{l}\text { - Destaca léxico } \\
\text { antigo/uso literário. }\end{array}$ \\
\hline & \multicolumn{2}{|c|}{ Referência ao próprio GR } & $\begin{array}{l}\text { “- um Monteiro Lobato, um José Lins } \\
\text { do Rego, uma Raquel de Queiroz, um } \\
\text { Luís Jardim, um José Américo de } \\
\text { Almeida, um Guimarães Rosa, que } \\
\text { mantém a verdade essencial da fala de } \\
\text { seus tipos sem descer ao servilismo da } \\
\text { fotografia” (p. 28) } \\
\text { "Nas páginas de Sagarana, de } \\
\text { Guimarães Rosa, vemos não só o em } \\
\text { antes (22, 53,63,71,302,318), como } \\
\text { também o de em antes (41, 95), } \\
\text { cruzamento de dantes ("de antes") com } \\
\text { em antes". } \\
\text { (p. 36) } \\
\text { "Na fala popular encontra-se até um em } \\
\text { desde, corrente pelo menos em Minas }\end{array}$ & $\begin{array}{l}\text { - Compara composição } \\
\text { de SLN com a de vários } \\
\text { autores "regionalistas": } \\
\text { adequação de norma } \\
\text { popular a registro } \\
\text { literário. } \\
\text { - Atesta uso vocabular } \\
\text { semelhante em outros } \\
\text { autores/regionalismos. }\end{array}$ & $\begin{array}{l}\text { - Assinala citação do } \\
\text { próprio escritor e de sua } \\
\text { obra (Sagarana) }\end{array}$ \\
\hline
\end{tabular}




\begin{tabular}{|l|l|l|}
\hline & $\begin{array}{l}\text { Gerais, pois aparece, mais de uma vez, } \\
\text { em Sagarana: p. 26, 207, 335" (p. 37) } \\
\text { "Guimarães Rosa, mostrando-se } \\
\text { embora, em geral, portuguesmente } \\
\text { correto, escreve: 'No fim de tudo, tem o } \\
\text { pátio, com os cochos, muito milho, na } \\
\text { fazenda' (Sagarana, p. 63). Cf. ainda p. } \\
93 \text { e 115" (p. 69) }\end{array}$ & \\
\hline
\end{tabular}

Fonte: elaborado pelo autor.

Antes de passarmos para as marcações nos contos e nas lendas de Simões, vale a pena ressaltar a preocupação de Guimarães Rosa com sua imagem pública. Parte considerável dos destaques do longo estudo introdutório diz respeito a comparações, principalmente no plano da linguagem (Quadro 2). Após uma passagem em que o autor é classificado por Holanda como um dos "bons" regionalistas que não fizeram caricatura do falar popular (a exemplo de Simões Lopes), há vários trechos confrontando ocorrências de construções gramaticalmente atípicas idênticas em Sagarana e nos Contos e Lendas. O que também não passou despercebido pelo leitor-escritor. Além disso, Rosa percorre o vocabulário e as notas de Aurélio Buarque de Holanda com atenção, sinalizando outras passagens em que é citado da mesma maneira. Essas afinidades formais, aparentemente fortuitas, identificadas pelo filólogo, devem ter estabelecido alguma empatia na leitura do autor mineiro. Talvez configurassem uma identidade de perspectiva literária, mesmo não assumida posteriormente. Mesmo que seja difícil comprovar essa interpretação, como dito no início deste ensaio, acredito que elas tenham ao menos feito com que Rosa projetasse sobre o texto simoniano, na experiência de leitura, suas próprias opções estéticas, ainda que inconscientemente. Essa parece a segunda chave de suas marcações, como veremos adiante. 
Quadro 1: Marcações de leitura de Guimarães Rosa no texto de Simões Lopes Neto

\begin{tabular}{|c|c|c|c|c|c|}
\hline Cor/tipo & \multicolumn{2}{|c|}{ Interesse } & \multirow[b]{2}{*}{ 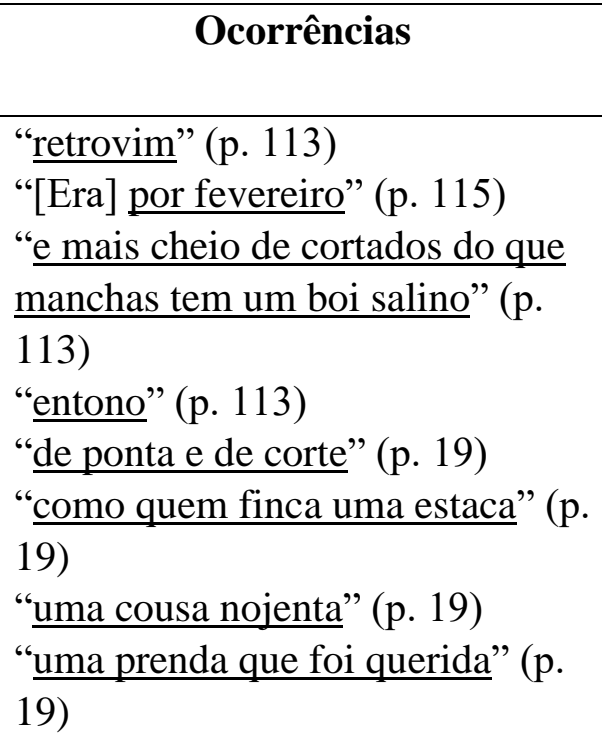 } & \multirow{2}{*}{$\begin{array}{l}\text { Funções do trecho no texto } \\
\text { - Uso de linguagem } \\
\text { popular/oral/regional na } \\
\text { fatura do texto - uso literal e } \\
\text { metafórico. }\end{array}$} & \multirow{2}{*}{\begin{tabular}{l}
\multicolumn{1}{c}{$\begin{array}{c}\text { Funções (possíveis) do } \\
\text { trecho na leitura }\end{array}$} \\
- Destaca vocabulário/ \\
expressões locais. \\
- Destaca vocabulário \\
regional na fatura do texto - \\
tópica: violência/sexo
\end{tabular}} \\
\hline Vermelho & $\begin{array}{l}\text { Regional } \\
\text { ismo } \\
\text { literário }\end{array}$ & $\begin{array}{l}\text { Cor local/ } \\
\text { Projeto } \\
\text { simoniano }\end{array}$ & & & \\
\hline \multirow[t]{2}{*}{ Azul } & \multirow{2}{*}{$\begin{array}{l}\text { Constru- } \\
\text { ções } \\
\text { estilísti- } \\
\text { cas }\end{array}$} & $\begin{array}{l}\text { Desloca-mentos } \\
\text { (sintaxe) }\end{array}$ & $\begin{array}{l}\text { “e sem olhar para ninguém” (p. } \\
133 \text { ) }\end{array}$ & - Recurso de estilo. & $\begin{array}{l}\text { - Destaca construção atípica } \\
\text { no nível da sintaxe. }\end{array}$ \\
\hline & & $\begin{array}{l}\text { Metáforas/ } \\
\text { eufemismos } \\
\text { (semântica) }\end{array}$ & $\begin{array}{l}\text { "tateou no negro" (p. 19) } \\
\text { "uma cruzeira numa toca" (p. 19) }\end{array}$ & $\begin{array}{l}\text { - Tratamento de temática } \\
\text { sexual com eufemismo. }\end{array}$ & $\begin{array}{l}\text { - Destaca uso metafórico da } \\
\text { linguagem regional para } \\
\text { abordar temática sexual. }\end{array}$ \\
\hline Lápis & $\begin{array}{l}\text { Investi- } \\
\text { gação de } \\
\text { lingua- } \\
\text { gem }\end{array}$ & Vocabulário & $\begin{array}{l}\text { "muitos casos: inté, entonce (ou } \\
\text { entonces), despois, saluço, } \\
\text { premeiro, dereito, proguntar, } \\
\text { malenconia, malino, sino-samão } \\
\text { ("signo-salomão"); sugigar, } \\
\text { Anrique, escuitar, contino, corgo, }\end{array}$ & $\begin{array}{l}\text { - Aproximação entre } \\
\text { literatura e fala popular } \\
\text { através de arcaísmos/erros. }\end{array}$ & - Destaca léxico antigo. \\
\hline
\end{tabular}




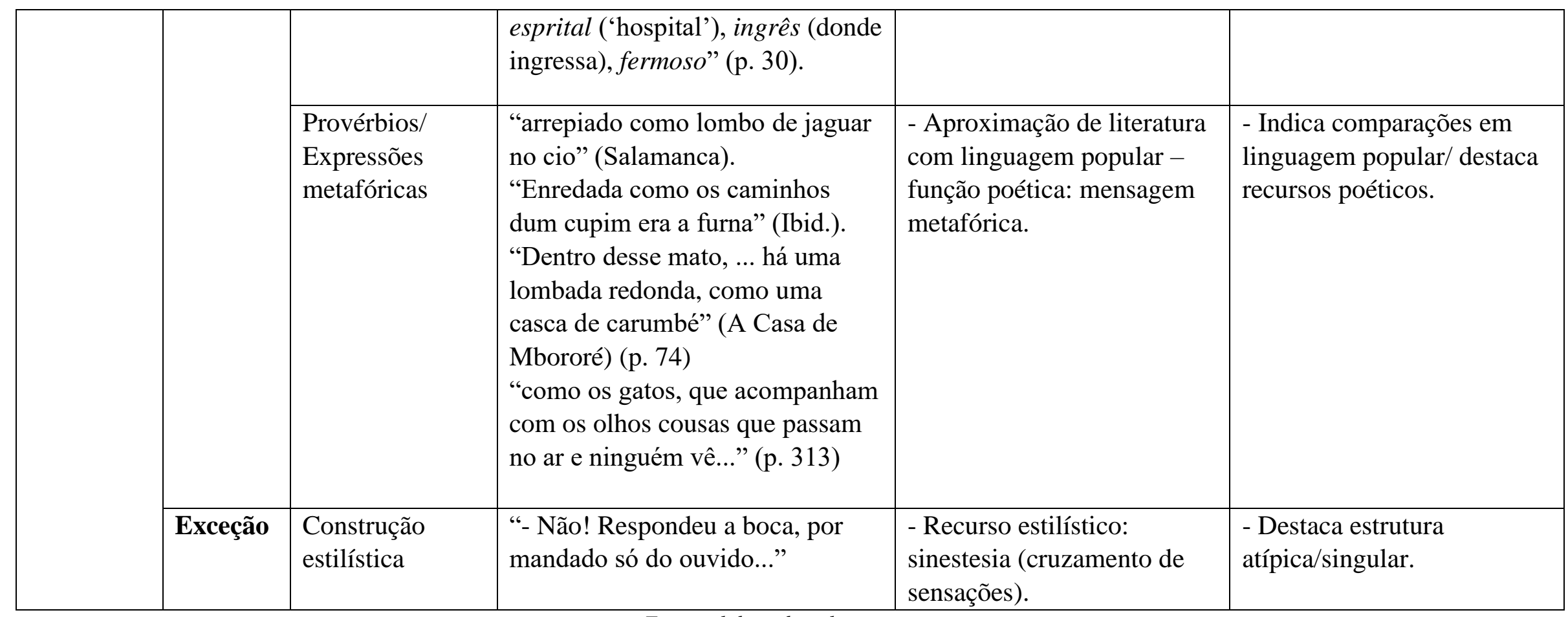

Fonte: elaborado pelo autor.

Seguindo a primeira chave, Rosa manifestou grande interesse pelos aspectos literários do regionalismo gaúcho. Pelas marcações feitas, parecia questionar a forma como Simões operou com vocabulário e expressões populares locais para atender a problemas gerais de composição. A função poética seria a principal resposta. Como a tradição oral é bastante visual, ela fornece elementos de fácil compreensão para a elaboração de metáforas. Daí o destaque em vermelho para construções como: "e mais cheio de cortados do que manchas tem um boi salino" (NETO, 1949, p. 113). Ou: "uma prenda [objeto de valor] que foi querida" (para falar da genitália do personagem Negro Bonifácio na perspectiva da amante Tudinha 
(NETO, 1949, p. 19). Em azul, o escritor sinalizou outras construções metafóricas que denotam o estilo simoniano, com a nítida função de abordar um tema delicado (de alcance universal), como a sexualidade, com eufemismo: "uma cruzeira numa toca" (NETO, 1949, p. 19), outra forma de se referir ao órgão sexual estraçalhado a facadas pela Tudinha no clímax do conto. Vale a pena dizer que a maioria desses destaques aponta para esquemas característicos da oralidade, o que parece confirmar a hipótese de Camila Rodrigues a respeito da relação entre sons e cores e a minha, neste artigo, sobre a extensão desse código a outras práticas pessoais de leitura. Se a norma padrão do português escrito não comportava uma regência como a encontrada em "era por fevereiro", seu uso no registro falado provavelmente acionava a experiência vocálica de Guimarães Rosa com a cultura sertaneja. Da mesma forma, um deslocamento na sintaxe como no exemplo já transcrito de "e sem olhar para ninguém" funcionaria perfeitamente no ritmo da fala.

Por fim, o escritor-leitor também destacou, com lápis grafite, provérbios utilizados por Simões nas lendas. Recurso bastante adequado à narração de motivos folclóricos, respeitando a premissa literária moderna de harmonia entre forma e conteúdo. Por exemplo: "arrepiado como lombo de jaguar no cio", da lenda "A Salamanca do Jarau", trecho reproduzido por Holanda na página 74. E quando as palavras marcadas têm sentido literal? Ainda assim, o sabor local conferiria verossimilhança ao assunto narrado. Por isso, provavelmente, a marcação em vermelho de regionalismos como "de ponta e de corte" (NETO, 1949, p. 19).

\section{Regionalismo e modernismo no campo literário}

A segunda chave de leitura, possivelmente estabelecida pela crítica de Holanda, levaria Rosa a encarar Simões como uma fonte. Daí sua preocupação com arcaísmos, hispanismos e léxico campeiro/regional. Jean Marie Goulemot chama de "fora-do-texto" o leitor e a situação de leitura, que ele enxerga como uma história coletiva e pessoal: "Desta última podemos discernir dois lados: o que nos liga ao contemporâneo e o que constitui nossa marca" (GOULEMOT, 2011, p. 110). Guimarães Rosa é reconhecido pelo seu trabalho com a linguagem literária, pela composição de neologismos, pela escolha cuidadosa das frases, pelo aproveitamento de traços da oralidade na escrita, enfim, pelo zelo com a fatura do texto, o que balizou, por exemplo, a dura crítica de Flávio Kothe, que definiu sua estética como "hipertrofia da forma" e "atrofia do conteúdo" (KOTHE, 2004, p. 425). De qualquer maneira, ainda que a linguagem literária de Simões não fosse 
tão elaborada ${ }^{6}$, o tratamento da forma apresenta um elo entre os autores, que foi muito provavelmente sentido pelo mineiro em sua prática de leitura. Talvez função da mesma sensibilidade modernista nascente na década de 1920, compartilhada por jovens intelectuais através do debate público e da troca de ideias entre as elites letradas locais, que fez com que Simões Lopes Neto fosse resgatado do limbo da história literária nacional. Não é à toa que Paulo Moreira (2012) classificou a estética rosiana como "modernismo localista".

A marca pessoal de Guimarães Rosa, portanto, também passa pela elaboração literária do regional, outro ponto de contato com o escritor gaúcho. Essa constatação pode parecer banal, mas é importante lembrar que a fortuna crítica do mineiro tratou de minorar seu vínculo com o regionalismo, o qual parece ter perdido espaço na prosa brasileira depois dos anos 1960. Dessa maneira, o rótulo não poderia caber àquele que é considerado, ainda hoje, um dos maiores autores brasileiros modernos: "a solução foi propor que o local em Guimarães Rosa era sumamente superficial, uma capa delgada que ocultava a análise 'das grandes questões humanas"” (MOREIRA, 2012, p. 27). Tática comum à crítica simoniana, como dito, e que encontrava balizas na obra. Em ambos os casos, o regional é retratado com realismo, mas sem se submeter ao "servilismo da fotografia", nos termos Holanda (1949, p. 28). A busca por uma forma próxima da lógica oral de narrar é para os dois autores o desdobramento desse compromisso. Por isso Simões foi usado por escritores como Erico Verissimo e Barbosa Lessa para descontruir uma visão mítica da história do Rio Grande do Sul, ainda que sua literatura seja recorrentemente apontada como uma das origens do gauchismo ufanista. Não é possível esconder a admiração de Simões Lopes pelo universo gauchesco. Mas seu ângulo de narração difere do ponto de vista eufórico a que Verissimo e Lessa se contrapuseram nos anos 1950, com a vantagem, para esses escritores, de também se destacar do pessimismo do conto republicano e do romance de 30 no Rio Grande do $\mathrm{Sul}^{7}$.

O projeto literário de Guimarães Rosa tem a mesma natureza crítica de seus contemporâneos gaúchos. Segundo Willi Bolle, ele teria chamado atenção para "o elemento mitificador na visão euclidiana da história, em que o discurso fúnebre eclipsa os que 'respiram' no sertão" (BOLLE, 2004, p. 28). Portanto, não se trata de uma afinidade meramente temática, mas também de perspectiva. A marcação tão intensa e

\footnotetext{
${ }^{6} \mathrm{Ou}$ dependesse mais do léxico popular regional, como veremos na próxima seção.

${ }^{7}$ No caso do conto republicano, a crítica dos anos 1950 se referia à obra de Alcides Maya, membro gaúcho da Academia Brasileira de Letras, que foi o principal alvo do modernismo literário no Rio Grande do Sul.
} 
detalhada do pequeno trecho do conto "O negro Bonifácio" pode ser compreendida como a projeção de sua própria relação com o regional no texto simoniano, além de seu potencial para explorar questões consideradas universais. Vejamos:

A Tudinha já não chorava, não; entre o Nadico, morto, e a velha Fermina estrebuchando, a morocha mais linda que tenho visto, saltou em cima do Bonifácio, tirou-lhe da mão sem força o facão e vazou os olhos do negro, retalhou-se a cara, de ponta e de corte... e por fim, espumando e rindo-se, desatinada - bonita, sempre! -, ajoelhou-se ao lado do corpo e pegando o facão como quem finca uma estaca, tateou no negro sobre a bexiga, pra baixo um pouco - vancê compreende?... - e uma, duas, dez, vinte, cinquenta vezes cravou o ferro afiado, como quem espicaça uma cruzeira numa toca... como quem quer estraçalhar uma cousa nojenta... como quem quer reduzir a miangos uma prenda que foi querida e na hora é odiada!... (NETO, 1949, p. 19).

Num pequeno parágrafo temos reunidos os interesses pela linguagem, no aproveitamento da oralidade e do léxico gauchesco no texto literário, e pelo conteúdo, o universo rural brasileiro e, principalmente, os motivos do erotismo e da vingança, numa mesma relação malsucedida entre homem e mulher. Não é preciso recorrer aos especialistas para lembrar o quanto esses problemas frequentam a literatura rosiana.

Em sentido diferente, o fora-do-texto também é uma história coletiva. Ele trata, no caso específico, justamente da trajetória e da situação do regionalismo no Brasil. Conforme Mariana Miggiolaro Chaguri apontou, nas décadas de 1930 e 1940, região e regionalismo eram temas permanentemente acionados pela intelectualidade, num esforço classificatório para o romance brasileiro que moldou outras visões disjuntivas: "esquerda e direita; engajamento e 'arte pela arte'; social e intimista, oposições que estiveram na base da produção e da circulação de diferentes obras, bem como orientaram o debate sobre a modernização da sociedade brasileira" (CHAGURI, 2014, p. 185). Daí as disputas entre os regionalismos ufanista, realista e modernista no Rio Grande do Sul. O primeiro era produto da conciliação simbólica das facções federalista e republicana da elite política regional, que criaram o mito conservador do gaúcho heroico para balizar o projeto varguista de tomada do poder central, no final dos anos 1920 (LEITE, 1972). O segundo foi a crítica mais dura ao primeiro. Próximo esteticamente ao romance nordestino de 1930 e politicamente à esquerda comunista, foi chamado de "disfórico" pelo escritor Cyro Martins porque se oporia à idealização literária do campesino rio-grandense, denunciando seu empobrecimento real (MARTINS, 1997). O terceiro nasceu no mesmo contexto do primeiro, mas teve vida mais longa, concorrendo com o segundo até os anos 1950. O modernismo gaúcho de temática regionalista acompanhava os movimentos de sua 
geração no restante do país, principalmente de escritores que, tal como Rosa, ou anteriormente Mário de Andrade, investiam em matéria folclórica no tema e na linguagem. Formalmente era inovador, mas seus usos políticos eram vários e, às vezes, conflitantes, já que podia ser praticado por gente como o socialista democrático Erico Verissimo ou o integralista Mansueto Bernardi.

De fato, cada autor/obra podia ser relacionar de maneira específica com as oposições regionalistas do campo literário, conforme levantadas por Chaguri. Guimarães Rosa era comumente considerado conservador na política e revolucionário na forma. Sua adesão ao varguismo e a atuação marcante no aparelho de Estado teriam feito dele, para muitos críticos, um intelectual orgânico, de perfil autoritário, o que seria reforçado pelo rótulo de "arte pela arte", facilmente atribuído a um projeto literário tão sofisticado: "como diplomata e como intelectual, destacou-se por seu perfil conservador" (KOTHE, 2004, p. 424-425). Trabalhos mais recentes, como o de Paulo Moreira, têm mostrado "redutora" a oposição entre política e arte naquele contexto, revelando na obra de Rosa uma crítica contundente à realidade social. Em ensaio clássico, Antonio Candido já havia chamado a atenção para esse aspecto. $\mathrm{O}$ autor enquadrou a literatura rosiana numa terceira fase do regionalismo brasileiro, o "super-regionalismo", que corresponderia "à consciência dilacerada do subdesenvolvimento". No plano estético, ele operaria "uma explosão do tipo de naturalismo que se baseia na referência a uma visão empírica do mundo" (CANDIDO, 2011, p. 195). De certa forma, uma atualização da antiga oposição modernista ao naturalismo cientificista, sobrevivente em certas expressões do chamado romance de 30 .

A leitura de Simões Lopes Neto por Guimarães Rosa revela, portanto, que as condições intelectuais de circulação da obra do escritor gaúcho continuavam passando pela história modernista da superação das convenções literárias dominantes na Primeira República, em sua última fase, mas também por um esforço de parcela da intelectualidade para a revisão de representações mitificadas da vida nacional. Depois dessa breve sondagem do fora-do-texto, o retorno ao documento explica a recepção simoniana na alta literatura do centro do país na década de 1950. As principais chaves da leitura de Rosa podem ser, então, percebidas como disposições compartilhadas, critérios de apreciação que poderiam resgatar um escritor esquecido ou jogar no ostracismo uma obra que já fora consagrada: aliança entre matéria local e problemas considerados universais; prosa poética; texto artesanal; representação verossímil, mas não naturalista da realidade social; abordagem da psicologia das personagens. Antonio Candido oferece um bom resumo do 
momento literário: “o que vemos agora, sob este aspecto [dimensão regional], é uma aflorada novelística marcada pelo refinamento técnico, graças ao qual as regiões se transfiguram e os seus contornos humanos se subvertem, levando os traços antes pitorescos a se descarnarem e adquirirem universalidade" (CANDIDO, 2011, p. 195).

Essa conclusão também demostra a grande sintonia entre os intelectuais gaúchos e a elite letrada atuante no centro do país. Todo o trabalho sobre a memória simoniana realizada naquele momento respondia aos critérios de valor correntes em nível nacional. De certa forma, os "modernismos de província" (MARQUES, 2011) precisam ser entendidos como uma constelação: suas especificidades não impediam a síntese, realizada em anos de correspondência e trânsito dos principais nomes da corrente, facilitada pela cooptação dos intelectuais pela classe dirigente (como indicado por Sérgio Miceli) e pelo projeto de modernização conservadora da Era Vargas. Mais do que isso, as redes modernistas, uma vez estabelecidas, forjaram os próprios crivos de legitimidade, recorrendo, para tanto, à invenção de tradições intelectuais: "Vendo-se a si próprios como responsáveis pela gestão do espólio cultural da nação, se dispõem a assumir o trabalho de conservação, difusão e manipulação dessa herança, aferrando-se à celebração de autores e obras que possam ser de alguma utilidade para o êxito dessa empreitada" (MICELI, 1979, p. 159). O fim do Estado Novo, aliás, não impunha um limite às pretensões desses agentes, que viam diante de si as oportunidades de reconhecimento público e de ocupação profissional se ampliarem e se diversificarem, com o crescimento do mercado de bens culturais e o fortalecimento do aparato de estado, incluindo áreas-chave como educação e cultura, pouco atendidas até então.

\section{Modernização literária e o regionalismo "plástico"}

O caso do documento analisado não deixa de ser sintomático dessa complexa configuração sociocultural pós-Vargas: um único volume que carrega em sua materialidade o encontro de intelectuais gaúchos com um nome em ascensão da elite letrada nordestina e com um escritor mineiro ainda não totalmente consagrado, mas bastante promissor. Além de, obviamente, um diálogo entre duas temporalidades literárias regionalistas, inscritas na produção do texto simoniano e na recepção rosiana. $\mathrm{O}$ que une tantos personagens, tempos, espaços e formas culturais? Talvez as posições homólogas no novo campo literário nacional, como busquei indicar na seção anterior. Talvez a mesma atitude diante de problemas históricos semelhantes, como a 
modernização da sociedade e os consequentes dilemas de salvaguarda e processamento da tradição.

É evidente que Rio Grande do Sul, Minas Gerais e Nordeste constituíam zonas periféricas da economia nacional nos anos 1950, centrada no eixo Rio-São Paulo - para onde muitos de seus novos escritores migravam e construíam suas carreiras. Mas também não eram, nem de longe, espaços irrelevantes, quer por seus desenvolvimentos recentes, quer pelo seu peso na história nacional. O que lhes dava condições semelhantes de autonomia relativa frente ao novo fluxo modernizador que vinha do exterior, através de instituições letradas, tradições intelectuais e agentes culturais capazes de processar a importação de padrões literários e bens simbólicos em nível local. De outro lado, provavelmente mais do que Rio de Janeiro e São Paulo, ainda precisavam acertar as contas com seu passado, redivivo na simplicidade de seus camponeses, em vastas áreas de seu interior rural (a "campanha" e o "sertão"), ou na memória de uma parcela expressiva de migrantes internos, que recrudesciam a tendência histórica de êxodo em busca de trabalho e oportunidades nos centros urbanos regionais. E, nesse sentido, os surtos industriais e de urbanização do Rio Grande e de Minas Gerais na Primeira República já haviam colocado o problema tradição $x$ modernidade na literatura dita regionalista, oferecendo modelos a seguir ou a ultrapassar ${ }^{8}$.

Pelos motivos estéticos já elencados, Simões Lopes Neto foi percebido, depois do modernismo, como um modelo a ser seguido. Conforme Ángel Rama, o impacto da modernização capitalista em zonas periféricas e/ou esquecidas da América Latina levou, desde o início do século XX, ao surgimento de movimentos consistentes de autores localistas, criollistas, nativistas, regionalistas etc. A primeira geração desses escritores, que publicaram suas obras por volta dos anos 1910, é conhecida por seu discurso defensivo e pela atitude reativa aos impulsos modernizantes. Mas alguns poucos deles conseguiram fugir a essa regra quando examinaram as tradições populares locais em declínio para revivê-las literariamente. São os "regionalistas plásticos", na classificação de Ángel Rama: "no pueden renunciar a ellas, pero pueden revisarlas a la luz de los

\footnotetext{
${ }^{8}$ Um reforço dessa homologia pode se encontrar no pareamento entre Simões Lopes Neto e o regionalista mineiro Afonso Arinos pelos modernistas gaúchos. Nos anos 1920, Arinos era tido pelo crítico Moysés Vellinho (que, inclusive, assinava suas crônicas literárias no Correio do Povo, de Porto Alegre, como Paulo Arinos), como um antídoto ao estilo rebuscado e artificial do conterrâneo Alcides Maya (como dito, principal alvo do modernismo no Sul). Um modelo para os escritores novos tão interessante quanto o velho Simões.
} 
cambios modernistas ${ }^{9}$, eligiendo aquellos componentes que se pueden adaptar al nuevo sistema en curso" (RAMA, 1989, p. 29). Não é necessário argumentar, a essa altura, que nosso autor gaúcho compartilhava da perspectiva. Esse fenômeno de aculturação, que lançava mão dos aportes modernos para revisar os conteúdos culturais locais, construindo não apenas sínteses, mas inovações, foi chamado por Ángel Rama de "transculturação narrativa". A geração de Guimarães Rosa, também classificada como de "herdeiros plásticos", teria explorado as estratégias de seus antecessores e amadurecido esse processo quando enfrentaram pressões de modernização capitalista e homogeneização cultural no Ocidente pós-Segunda Guerra ${ }^{10}$. A principal diferença entre as duas gerações, nesse âmbito, se encontrava nos limites da apropriação literária do registro popular de língua (e de sua consequente ampliação de perspectiva cultural). A primeira se concentraria no léxico, na prosódia e na sintaxe da língua regional, posta em oposição, nas obras, à língua culta do escritor ou do narrador. Na segunda, ao contrário, os grandes escritores comporiam sua linguagem literária a partir dos sistemas linguísticos das comunidades rurais abordadas, sem "imitar desde fuera un habla regional, sino elaborarla desde dentro con una finalidade artística" (RAMA, 1989, p. 43). Simões Lopes Neto procedeu, surpreendentemente, à segunda maneira, como sabemos, ainda que seu campo de atuação exigisse maior acento no léxico popular do que o de Guimarães Rosa ${ }^{11}$.

Como sugere Carlo Ginzburg, "as semelhanças transculturais podem ajudar a compreender as especificidades dos fenômenos de que partiram" (GINZBURG, 2001, p. 87). O mais interessante dessa comparação entre as gerações de Simões Lopes e de Guimarães Rosa à luz das teorias de Ángel Rama, a meu ver, não é mostrar a recorrência latino-americana de encontros literários entre elas, nem apontar para sua agora evidente linha de continuidade, independente das relações concretas autor-autor que são mapeáveis (ou efetivadas conscientemente). Interessa sobretudo porque realça, ainda mais, a especificidade estética simonina em seu contexto, a qual podemos, sem medo de cair na ideologia romântica do gênio criador, chamar de originalidade. Cruzando leituras e

\footnotetext{
${ }^{9}$ Vale lembrar que na historiografia literária hispânica, o termo "modernista" se refere a correntes poéticas da virada do século, como o simbolismo e o parnasianismo, contemporâneas a esses autores. Chama-se de "vanguardismo" o movimento equivalente ao nosso modernismo, em função da importação das proposições estéticas das vanguardas europeias.

${ }^{10}$ Se Ángel Rama não conheceu e, portanto, não chegou a citar Simões Lopes entre os escritores plásticos de sua geração, Guimarães Rosa aparece em seu ensaio como um dos principais exemplos de herdeiros dessa tendência nos anos 1950; pareado, principalmente, ao escritor mexicano Juan Rulfo.

11 Traço que exigia tanto dos regionalistas defensivos como dos plásticos a uso de glossários para guiar a leitura. Algo superado pela geração de Rosa, conforme também notou Ángel Rama. No caso de Simões, a distância no tempo reforçou a necessidade, o que justifica o aparato crítico da edição de Holanda.
} 
tradições literárias antecedentes, inclusive transnacionais, como a poesia gauchesca rioplatense do oitocentos e a narrativas lendárias folcloristas da Primeira República brasileira, o escritor pelotense chegou primeiro aos resultados celebrados para a geração de Guimarães Rosa, através de um foco narrativo "mediador", que concilia passado e presente, campo e cidade, tradição e modernidade. No personagem-narrador popular (letrado ou "vivido"/sábio) se efetiva a transculturação "en él se deposita um legado cultural y sobre él se arquictetura para poder transmitir-se a una nueva instancia del desarrollo, ahora modernizado" (RAMA, 1989, p. 100). A mesma conclusão de Ángel Rama sobre o Riobaldo de Guimarães Rosa cabe ao Blau Nunes de Simões Lopes: seu longo discurso "no es un monólogo, sino una comunicación a un 'senhor' que por lo tanto está presente dentro del texto" (RAMA, 1989, p. 100). Basta lembrar a recorrente interlocução entre o narrador e um destinatário fictício implícito, algo característico da função fática do discurso oral: "Patrício, escuite!" (NETO, 1949, p. 136); "Vancê acredita?..." (NETO, 1949, p. 142); "Vancê reparou?" (NETO, 1949, p. 152); "Se vancê fosse daquele tempo, eu calava-me, porque não lhe contaria novidade" (NETO, 1949, p. 163), para ficarmos em alguns exemplos.

\section{Considerações finais}

A pergunta inicial deste ensaio, acerca da influência do autor gaúcho sobre o mineiro, pode ser impossível de ser respondida se levarmos em conta as dinâmicas de filiações individuais no campo intelectual, como dito. Mas talvez tenhamos chegado, pelo menos, a algumas ideias gerais sobre a transmissão social do legado "plástico" simoniano para seus leitores modernistas-regionalistas no Brasil, não apenas no plano da construção a posteriori das condições críticas e editoriais para sua apreciação (com o projeto de reparação articulado pelos gaúchos), mas no nível das sensibilidades literárias historicamente compartilhadas. Mesmo que entendamos a parte final do percurso que construí neste ensaio como uma grande especulação, no sentido de levantar livremente hipóteses e explorá-las à luz da história e da teoria, a análise inicial da leitura documentada de Guimarães Rosa revela indubitavelmente afinidades literárias percebidas pelo próprio escritor. Mesmo que isso ainda seja insuficiente para afirmar Simões Lopes Neto como a principal fonte do achado narrativo de Guimarães Rosa, o reforço da semelhança em profundidade e o atestado do caráter transculturador da obra simoniana dão sentido à própria natureza do problema do influxo, tantas vezes sugerido por críticos de ambos os autores. A discussão, infelizmente, pode não chegar a uma resposta 
conclusiva, mas acredito que aprendemos algo de novo cada vez que a enfrentamos com fontes inéditas e experimentação metodológica.

\section{Referências bibliográficas}

BOLLE, Willi. Grandesertão.br: o romance de formação. São Paulo: Duas Cidades, Editora 34, 2004.

CANDIDO, Antonio. Literatura e subdesenvolvimento. In: CANDIDO, Antonio. A educação pela noite. 6. ed. Rio de Janeiro: Ouro sobre Azul, 2011, p. 169-196.

CHAGURI, Mariana Miggiolaro. O Norte e o Sul: região e regionalismo em meados do século XX. Sociologia \& Antropologia, Rio de Janeiro, v. 4, n. 1, jun. 2014, p. 185-206.

CORADINI, Odaci Luiz. As missões da "cultura" e da "política": confrontos e reconversões de elites culturais e políticas no Rio Grande do Sul (1920-1960). Estudos históricos, Rio de Janeiro, n. 32, 2003, p. 125-144.

FISCHER, Luís Augusto. Simões Lopes Neto e Guimarães Rosa: a literatura e o luto no sertão. Teresa, São Paulo, n. 14, 2014, p.175-190.

GENETTE, Gérard. Paratextos editoriais. São Paulo: Ateliê Editorial, 2009.

GINZBURG, Carlo. Olhos de madeira: nove reflexões sobre a distância. São Paulo: Companhia das Letras, 2001.

GOULEMOT, Jean Marie. Da leitura como produção de sentidos. In: CHARTIER, Roger (org.). Práticas de leitura. $5^{\text {a }}$ ed. São Paulo: Estação Liberdade, 2011, p. 107-116.

HOLANDA, Aurélio Buarque de. Introdução. In: NETO, João Simões Lopes. Contos Gauchescos e Lendas do Sul. Porto Alegre: Editora Globo, 1949, pp. 25-113.

KOTHE, Flávio R. O cânone republicano, v. 2. Brasília: UnB, 2004.

MARQUES, Ivan. Cenas de um modernismo de província: Drummond e outros rapazes de Belo Horizonte. São Paulo: Editora 34, 2011.

MARTINS, Cyro. Visão crítica do regionalismo. In: MARTINS, Cyro. Sem rumo. $6^{\text {a }}$ ed. Porto Alegre: Movimento, 1997, p. 14-30.

MICELI, Sergio. Intelectuais e Classe dirigente no Brasil (1920-1945). São Paulo: Difel, 1979.

MOREIRA, Paulo. Modernismo localista das Américas: os contos de Faulkner, Guimarães Rosa e Rulfo. Belo Horizonte: Editora UFMG, 2012.

NETO, João Simões Lopes. Contos Gauchescos e Lendas do Sul. Porto Alegre: Editora Globo, 1949. 
RAMA, Ángel. Transculturación narrativa en America Latina. 2. ed. Montevideo: Arca Editorial, 1989.

RODRIGUES, Camila. Escrevendo a lápis de cor: infância e história na escritura de Guimarães Rosa. Tese (Doutorado em História), Programa de Pós-Graduação em História, Faculdade de Filosofia, Letras e Ciências Humanas, Universidade de São Paulo, São Paulo, 2014.

VASCONCELOS, Sandra Guardini Teixeira. "Os Mundos de Rosa". Dossiê 30 Anos sem Guimarães Rosa. Revista USP, n. 36, dez. 1997/fev., p. 78-87, 1998.

ZALLA, Jocelito. A invenção de Simões Lopes Neto: literatura e memória histórica no sul do Brasil. Tese (Doutorado em História), Programa de Pós-Graduação em História Social, Instituto de História, Universidade Federal do Rio de Janeiro, Rio de Janeiro, 2018. 